\title{
Patrimoine et culture industriels en milieu rural : quelles spécificités?
}

Industrial heritage and culture in rural areas: any specificities?

\section{Simon Edelblutte et Johann Legrand}

\section{OpenEdition}

\section{Journals}

Édition électronique

URL : http://journals.openedition.org/rge/3683

DOI : $10.4000 /$ rge.3683

ISSN : 2108-6478

Éditeur

Association des géographes de l'Est

Édition imprimée

Date de publication : 31 décembre 2012

ISSN : 0035-3213

Référence électronique

Simon Edelblutte et Johann Legrand, «Patrimoine et culture industriels en milieu rural : quelles spécificités? », Revue Géographique de l'Est [En ligne], vol. 52 / 3-4 | 2012, mis en ligne le 02 juillet 2013, consulté le 10 décembre 2020. URL : http://journals.openedition.org/rge/3683 ; DOI : https://doi.org/ $10.4000 /$ rge.3683

Ce document a été généré automatiquement le 10 décembre 2020.

Tous droits réservés 


\title{
Patrimoine et culture industriels en milieu rural : quelles spécificités?
}

Industrial heritage and culture in rural areas: any specificities?

\author{
Simon Edelblutte et Johann Legrand
}

\section{Introduction}

1 Pendant longtemps, les traces et vestiges industriels n'ont pas été considérés comme un véritable patrimoine. Ainsi, et à propos des biens patrimoniaux, F. Choay qualifiait-elle, pourtant déjà en 1992, les lieux de l'industrie de "dérisoires» (p. 181), tandis que J.M. Leniaud (1992), cité par V. Veschambre en 2005, précise que l'industrie est un "domaine dans lequel il apparaît [...] que le patrimoine ne va pas de soi » (p. 511). Les raisons de ce retard de la patrimonialisation de l'industrie sont bien connues et vont du traumatisme économique et social que la fermeture du site a provoqué, à l'ambiance de sites abandonnés (pollutions, dangers..) en passant par la relative jeunesse de ces vestiges (essentiellement XIX ${ }^{\text {ème }}$ et XX ${ }^{\text {ème }}$ siècles) et le symbole de l'échec d'un modèle de développement représenté par l'usine fermée. Passée la phase de deuil, pendant laquelle on ne fait rien d'autre qu'attendre une éventuelle reprise économique en niant le passé industriel, le patrimoine industriel est enfin reconnu, plus ou moins tôt selon les États, avec une avance certaine pour le Royaume-Uni, précurseur industriel (Edelblutte, 2009a).

2 Par la suite, et comme les autres types de patrimoine, la notion de patrimoine industriel s'élargit des simples objets (anciennes machines, locomotives...) aux bâtiments de production (usines) jusqu'au paysage industriel en passant par la villeusine $^{1}$. C'est cet élargissement, à la fois typologique, chronologique (Veschambre, 2007) et surtout spatial (de l'objet au site et jusqu'au paysage et au territoire, objets éminemment géographiques), qui donne sa place aux géographes dans ces travaux. L'élargissement peut d'ailleurs être aussi étendu aux types de réutilisation. En effet, la patrimonialisation, et c'est particulièrement vrai dans le domaine du patrimoine industriel a priori moins attractif que les patrimoines militaire, civil ou religieux, ne 
passe pas forcément par une muséification, mais plutôt par une réutilisation à d'autres fins tout en préservant le caractère patrimonial du bâtiment. Enfin, la notion de patrimoine industriel est de plus en plus liée au tissu industriel vivant, c'est-à-dire que, à une époque où le patrimoine immatériel est reconnu par l'UNESCO, les savoir-faire industriels, comme une certaine culture entrepreneuriale et industrielle, peuvent être considérés comme un patrimoine vivant qu'il faut protéger, au même titre qu'une église ou un monument. Dans les pays ou les régions anciennement industrialisés, cette conception peut être rapprochée des discours politiques de sauvegarde du tissu industriel, voire de ré-industrialisation.

3 Les vestiges industriels qui attirent en premier lieu l'attention et la protection patrimoniales répondent à plusieurs caractéristiques :

- l'ancienneté : les vestiges les plus anciens, notamment ceux de la proto-industrie, ne sont pas toujours rattachés à l'aventure industrielle elle-même et n'en subissent donc pas les perceptions négatives liées à son effondrement; ils sont souvent les premiers valorisés, comme les manufactures royales du XVIII ${ }^{\text {ème }}$ siècle ;

- la visibilité : les grosses usines, éléments spectaculaires bien inscrits dans le paysage, sont devenues, à condition de ne pas avoir été immédiatement détruites après la fermeture, des sortes de totems emblématiques de l'apogée industrielle et sont difficilement effaçables (usine sidérurgique de Völklingen, Sarre, Allemagne);

- l'originalité : l'architecture de l'usine, plus ou moins soignée et originale, joue beaucoup dans la conservation ou non du bâtiment. Manufactures proto-industrielles, usines " château-fort ", dites travesties (Bergeron \& Dorel-Ferré, 1996), attirent plus l'attention que les usines au toit à sheds de la fin du XIX ${ }^{\text {ème }}$ siècle ou encore que les hangars fonctionnalistes actuels ;

7 - la rareté : un modèle architectural rare ou peu répandu dans une région donnée, comme l'usine de Vincey, sur la commune de Portieux (Lorraine), dernière usine en briques rouges du textile vosgien, ou encore une fabrication spécifique ayant nécessité un bâtiment très particulier, comme la soufflerie de l'office National d'Études et de Recherches Aérospatiales (ONERA) à Meudon (île-de-France), sont aussi de fortes motivations à la patrimonialisation ;

- l'homogénéité : un ensemble architectural et urbanistique cohérent et peu modifié depuis la fermeture ou le désengagement de son instigateur, l'usine, a plus de chances d'être préservé qu'un ensemble hétéroclite de traces industrielles dispersées au sein d'une ville; les villes-usines paternalistes des première et seconde révolutions industrielles (New-Lanark en Écosse, Saltaire en Angleterre, "Batavilles ${ }^{2}$ " un peu partout en Europe) ou encore les utopies proto-industrielles (saline royale d'Arc-etSenans, Franche-Comté) ou paternalistes (familistère de Guise, Picardie), sont représentatives de ces ensembles homogènes ;

l'accessibilité : pour pouvoir valoriser ce patrimoine industriel, surtout si les conditions répertoriées ci-dessus sont absentes totalement ou en partie, l'accessibilité $\mathrm{du}$ site est primordiale, notamment pour lui retrouver une fonction (commerce, loisirs, culture...) permettant de conserver l'héritage industriel. Un site enclavé n'a effectivement que des chances réduites de pouvoir attirer une activité relais.

10 Ainsi, les petites usines, le patrimoine industriel annexe (cités ouvrières, aménagements hydrauliques...), les bâtiments peu spectaculaires, les usines les plus banales (comme celles au toit à sheds), les sites moins accessibles... sont les moins à 
même d'être valorisés, si ce n'est protégés. Or c'est justement en zone rurale que ces dernières caractéristiques sont les plus présentes. De plus, en milieu rural, la problématique du développement local fait en général peu de place à l'industriel, passé ou futur, considéré comme annexe par rapport aux question d'accessibilité, d'agriculture, de services, de tourisme, de paysage ou même d'identité locale.

11 Certes, la complexité et la variété du milieu rural, plus ou moins proche des grandes métropoles, autorisent une gamme très large des implantations industrielles ( $\mathrm{Holz} \&$ Houssel, 2002) et rendent difficiles les généralisations. Ainsi les espaces ruraux proches des villes peuvent devenir le réceptacle d'activités industrielles quittant la ville, pour des raisons de place et d'accessibilité, pour des Zones d'Activités (ZA) détachées du tissu urbain ; il est néanmoins difficile de considérer ces dernières comme rurales. De même, le milieu rural profond a parfois accueilli, cette fois pour des raisons de disponibilité de la matière première ou de l'énergie, les implantations protoindustrielles les plus prisées aujourd'hui en termes de patrimoine, comme la saline royale d'Arc-et-Senans déjà citée. Néanmoins, la grande majorité des traces industrielles en milieu rural peut être qualifiée de vernaculaire. En effet, comme il existe un patrimoine vernaculaire, petit patrimoine fait de calvaires, de lavoirs, de petits objets ou aménagements du quotidien, particulièrement mis en valeur dans la plupart des villages européens, il peut exister un patrimoine industriel vernaculaire, fait de petites usines oubliées, de cités ouvrières isolées, de villages-usines endormis, d'aménagements ténus, de ruines peu accessibles. Beaucoup de ces traces industrielles font d'ailleurs partie d'un patrimoine industriel dit immergé par Bergeron \& DorelFerré (1996), ce qui signifie qu'elles sont discrètes et difficiles à identifier en tant que telles.

C'est essentiellement de ce petit patrimoine industriel et notamment de sa place dans les paysages et les territoires ruraux qu'il sera question ici. En s'appuyant sur de nombreux exemples illustrés et commentés, pris en Europe occidentale anciennement industrialisée, mais plus particulièrement en France et en Lorraine, l'approche utilisée pour ce travail est fondée sur l'analyse des paysages industriels. Ces derniers regroupent tous les éléments habituels composant le patrimoine industriel, de l'usine à la cité ouvrière en passant par le crassier ou la coopérative. Cette approche paysagère, largement développée autour de thèmes principalement ruraux dans les débuts de la géographie universitaire, a été ensuite quelque peu rejetée, notamment en France, en raison du développement d'une géographie plus quantitative qui se voulait avant tout scientifique. Dans cette approche, dominante dans la seconde moitié du XX ${ }^{\text {ème }}$ siècle, le paysage, considéré comme non mesurable ou quantifiable et, de plus, soumis aux perceptions subjectives de ses observateurs, n'avait pas sa place (Edelblutte, 2012). Depuis la fin du XX⿳亠丷⿵冂丶 ${ }^{2}$ siècle et la remise en cause des modèles économiques et scientifiques développés durent les Trente Glorieuses, le paysage, d'ailleurs reconnu en France par la loi (loi paysage de 1993), est redevenu un objet d'étude essentiel en géographie. Intégrant les apports de la géographie culturelle en matière de perception, de représentation et d'identité (Frémont, 1976), mais aussi les héritages de l'École vidalienne, il est considéré aujourd'hui comme «l'expression observable par les sens, à la surface de la Terre, de la combinaison entre la nature, les techniques et la culture des Hommes " (Pitte, 1983, rééd. 2001, p. 19). Élément de l'identité locale, il est comme un livre ouvert sur l'espace car il est une somme d'éléments passés et actuels, un palimpseste de l'histoire (Chevallier, 1976) ou encore « une sorte de mémoire où s'enregistre et se totalise 
l'histoire des visées successives de l'homme sur la terre » (Béguin, 1995, p. 50). Son utilisation est donc particulièrement pertinente pour une étude du patrimoine.

À travers cette approche, il s'agira donc de définir, de décrire et d'évaluer ce patrimoine industriel et ainsi d'en déterminer les spécificités par rapport au patrimoine industrialo-urbain. Après avoir esquissé le potentiel patrimonial, c'est-àdire réalisé un inventaire rapide des différents types de traces industrielles en milieu rural, ce travail s'attachera à montrer comment s'est constitué ce patrimoine industriel, plus d'une façon lente et progressive faite d'abandons et d'oublis que de fermetures médiatisées et de modifications brutales. Enfin, il s'agira de montrer, qu'aux côtés d'une occultation et d'un abandon toujours très présents, il existe, en matière de préservation patrimoniale, des actions très variées. Ce sont souvent des initiatives locales, allant du domaine privé et donc très ponctuelles, au domaine public, dans le cadre de collectivités locales motivées par ce sujet pour des raisons à la fois économiques, culturelles et identitaires.

\section{Un potentiel patrimonial important et méconnu}

En Europe, la transition d'un monde majoritairement rural à un monde majoritairement urbain, fondée sur le passage du taux d'urbanisation au-dessus de 50\%, s'effectue entre les années 1870 (Royaume-Uni) et les années 1950 ; la France basculant durant l'Entre-deux-guerres (Fabriès-Verfaillie, Stragiotti \& Jouve, 2000). Si l'artisanat, varié et disséminé dans chaque village, a été une des caractéristiques majeures de ce monde rural qui tendait vers l'autarcie, il existait aussi des établissements, soit plus vastes (les manufactures, déjà évoquées), soit plus petits mais déjà mécanisés (les moulins) ou encore des concentrations de paysans-ouvriers à domicile qui ne s'apparentaient déjà plus à de l'artisanat. De plus, ces éléments proto-industriels sont souvent, soit le fondement d'une industrialisation diffuse sous forme de districts, où la patrimonialisation est en général faible, soit la base d'implantations plus imposantes et plus ponctuelles ayant généré des villages-usines, au potentiel patrimonial souvent plus mis en valeur.

\section{A. Le milieu rural, terre de proto-industrie}

La proto-industrie existait en ville (le textile des villes drapantes de Flandre ou encore les Canuts de Lyon), mais elle a surtout marqué les territoires ruraux, d'une façon plus générale que l'industrie des révolutions industrielles.

C'est d'abord le travail à domicile qui, en créant des territoires particuliers, s'inscrit de façon ténue dans le paysage. Ce travail à domicile est le plus souvent lié à des paysans qui, à la morte saison, complètent leurs revenus en travaillant le textile (filature et/ou tissage). Il est particulièrement présent en montagne où la longue saison d'hiver laisse du temps pour le travail textile. Il est lié à des négociants de villes voisines qui, à l'automne, apportent le travail à effectuer et le récupèrent au printemps, construisant une sorte de territoire proto-industriel en réseau.

Parfois, une certaine spécialisation s'opère et le paysan, fileur ou tisserand, adapte son habitation à l'activité textile qui devient principale. La trace paysagère de cette activité, répandue dans de nombreuses campagnes d'Europe, reste néanmoins discrète. Il s'agit 
le plus souvent d'une rangée de maisons, souvent petites, mais dont certaines caractéristiques trahissent l'emploi proto-industriel plus qu'agricole (photo 1).

Photo 1 : Les maisons ateliers des tisserands d'Arlington Row à Bibury, Gloucestershire, Angleterre, Royaume-Uni

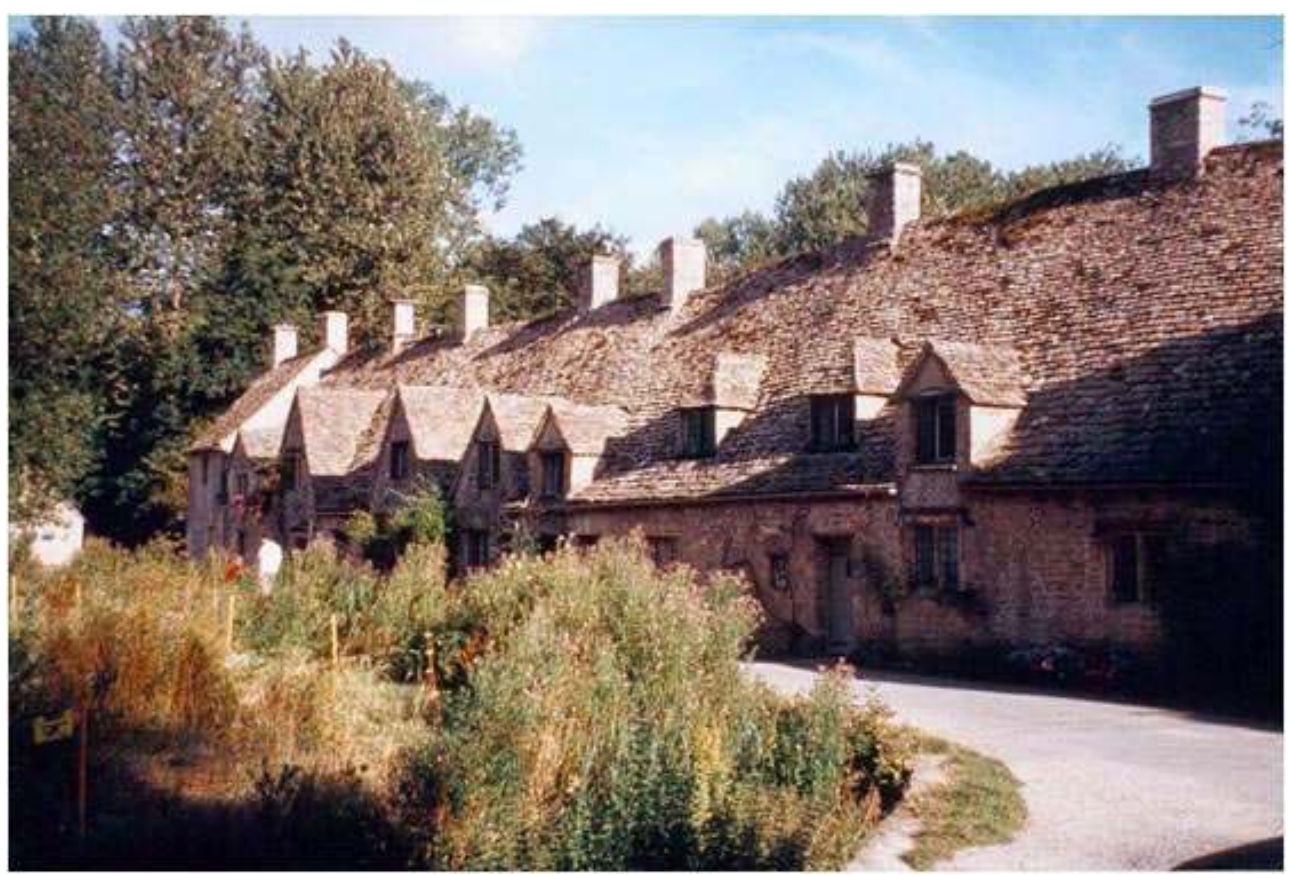

Photo : Edelblutte, 2002

Les maisons de tisserands de Bibury, construites au XVIIème siècle, présentent un grenier largement surélevé pour abriter des métiers actionnés par les habitants vivant au rez-de-chaussée.

Un des autres éléments proto-industriels parmi les plus répandus en milieu rural est le moulin. Petit bâtiment employant peu de monde, son caractère proto-industriel lui vient de l'utilisation d'une machine, liée à la force hydraulique. Sa signature paysagère, un peu plus sensible que les maisons-ateliers vues précédemment, est liée à son site, en bordure d'un cours d'eau (et donc souvent détaché du village), et à sa roue actionnée par le cours d'eau. Cette configuration implique d'ailleurs quelques aménagements annexes, tels qu'un seuil ou barrage, un canal d'alimentation des vannes, un canal de fuite, dont le caractère patrimonial est aujourd'hui reconnu. Il est aussi souvent le point d'origine d'une future usine, plus ou moins développée (photo 2), quittant ainsi le monde de la proto-industrie. 
Photo 2 : Un ancien moulin devenu filature sur la Nims, à Bitburg, Rhénanie-Palatinat, Allemagne

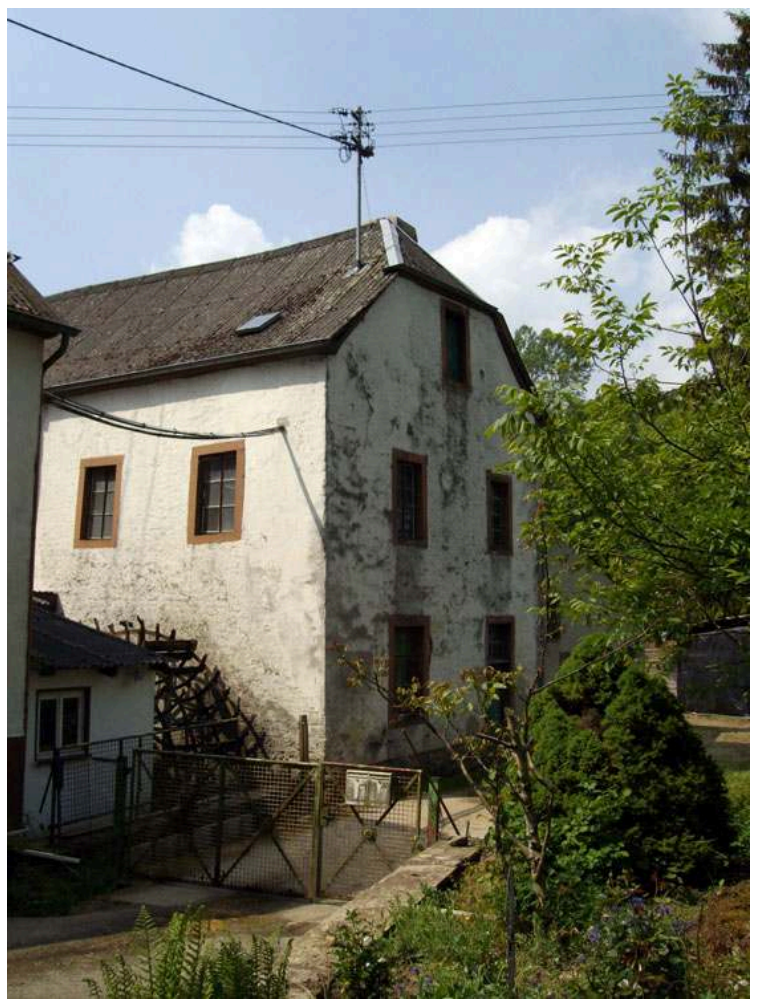

Photo : Edelblutte, 2011

Cette petite filature est l'héritière d'un moulin construit dans la première partie du XIXème siècle par le village de Stahl (aujourd'hui dans la municipalité de Bitburg) et d'abord utilisé comme moulin à plâtre, à papier puis à foulon. La roue métallique du moulin (puis de la filature) est toujours visible Le bâtiment à étages et à nombreuses fenêtres, couvert d'un toit à demi-croupes, est typique de l'architecture industrielle du début du XIXème siècle.

\section{B. Le développement d'une industrie diffuse sans forte concentration}

À partir du XVIII ${ }^{\text {ème }}$ siècle au Royaume-Uni et du XIX ème siècle sur le continent européen, s'opère le passage à l'industrialisation. En milieu rural, ce passage s'opère de deux façons, produisant deux types de paysages et de territoires, au potentiel patrimonial différent.

- Affaiblie face à la concentration financière et technique liée aux révolutions industrielles, la proto-industrie rurale évolue parfois vers une industrialisation dite diffuse, par un passage progressif des méthodes artisanales aux méthodes industrielles sur un territoire que la population, importante à son maximum démographique rural au cours du XIX ${ }^{\text {ème }}$ siècle et enracinée, ne veut pas quitter. Cette industrialisation du milieu rural, "souvent sous-estimée » (Houssel, 1992, p. 173), aboutit fréquemment à la formation de districts industriels caractérisés par la présence d'usines dans des villages disséminés sur un territoire relativement restreint, de la taille d'un canton ou d'un arrondissement. Dans cette configuration, les usines, jamais très grosses, ne s'entourent pas ou très peu de cités ouvrières, puisque le passage à l'industrie s'est fait progressivement avec de la main d'œuvre locale. Tout au plus un étage de l'usine peut-il être réservé à des dortoirs pour les ouvrières, comme dans les 
usines-internats des vallées ardéchoises travaillant au moulinage de la soie. L'industrie est donc le vecteur par lequel la population s'est maintenue sur ces territoires et elle leur est consubstantiellement liée. De cette façon, "l'activité industrielle s'insère parfaitement dans l'économie rurale jusqu'à s'y diluer, à en perdre justement son caractère industriel " (Nacé Ch. \& Nacé J-R., 2008, p. 283); elle fait ainsi totalement partie de l'identité des populations locales et cela lui donne, au moment du déclin puis de la reconversion, une importance patrimoniale.

- L'industrialisation du milieu rural peut s'effectuer aussi beaucoup plus brutalement, avec des implantations ex-nihilo, liées à la présence de matières premières (minerai, bois, sel...) ou de source d'énergie (charbon, force hydraulique) ou encore d'une bonne accessibilité (voie ferrée, canal). Si certains de ces sites (en raison de leur réussite économique et donc de l'attraction qu'ils provoquent en termes d'autres activités industrielles, de services et de population) forment très vite des villes-usines (Edelblutte, 2009b et 2010b), beaucoup, s'ils sont certes bien obligés de s'entourer de cités ouvrières pour abriter une main d'œuvre beaucoup moins mobile autrefois qu'aujourd'hui, restent néanmoins modestes et forment des agglomérations réduites de quelques centaines d'habitants au maximum. Il se crée ainsi, en milieu rural, des villages-usines, petites agglomérations de cités ouvrières et de quelques services entourant l'usine qui en est à l'origine (encadré 1).

Encadré 1 : Le village-usine de la verrerie durant les années 1950 à Gironcourt-sur-Vraine, Vosges
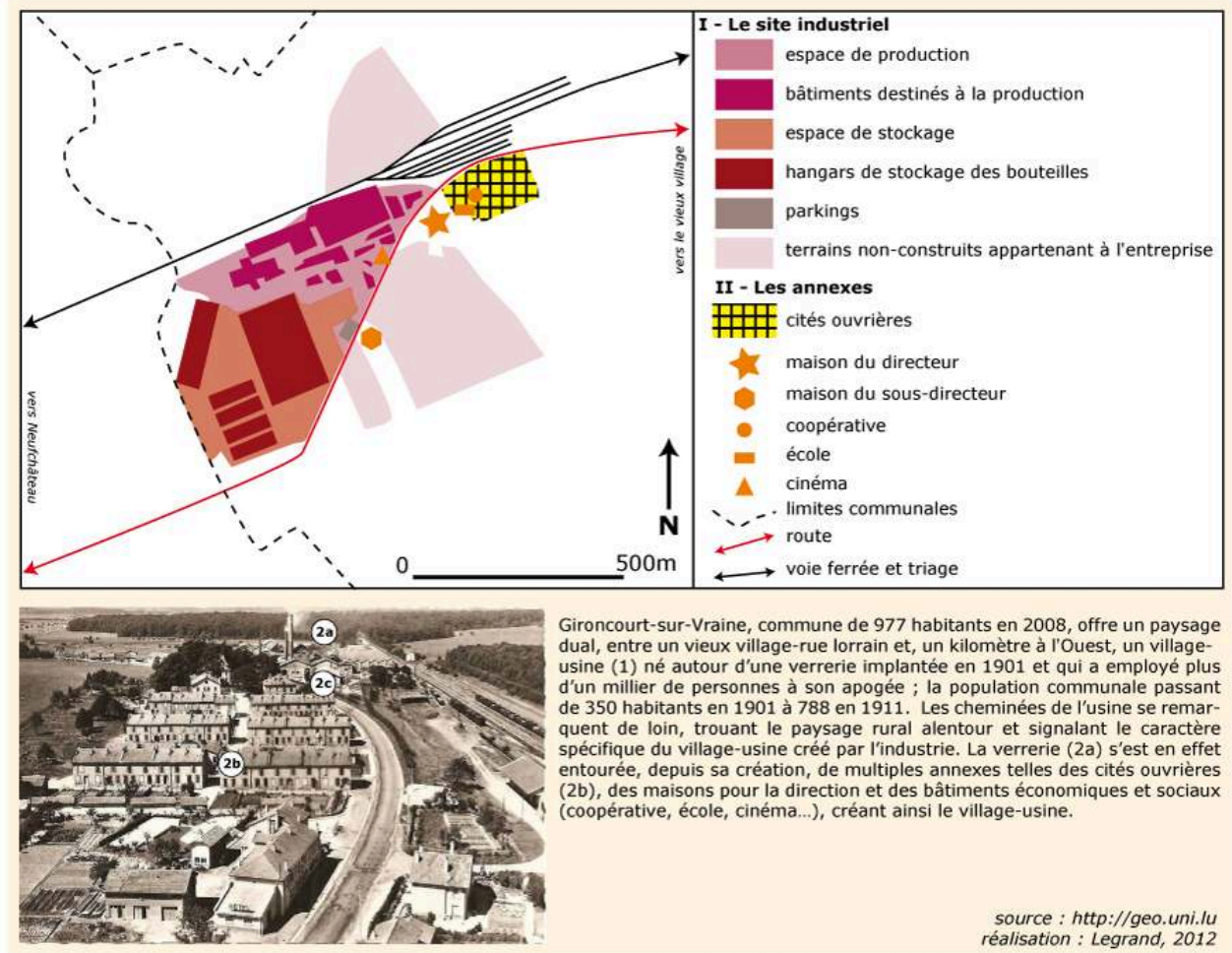

22 L'industrie en milieu rural offre donc des paysages toujours moins spectaculaires que les industries périurbaines ou mieux que les villes-usines nées autour de plus grosses usines. Néanmoins, même si c'est de manière plus diffuse et plus ponctuelle, cette activité a profondément marqué certains territoires ruraux qui en conservent la marque bien après sa disparition. 


\section{Abandon, oubli et absence d'enjeu} beaucoup de sites industriels fermés, loin de grands axes et dans des régions rurales peu dynamiques, sont en fait abandonnés et, sites en déshérence, forment des friches non traitées qui peuvent alors perdurer de très nombreuses années, voire plus d'un siècle (photo 3 ).

Photo 3 : L'ancien haut-fourneau de Buré-la-Forge, une micro-friche rurale ruinée à Allondrelle-laMalmaison, Meurthe-et-Moselle

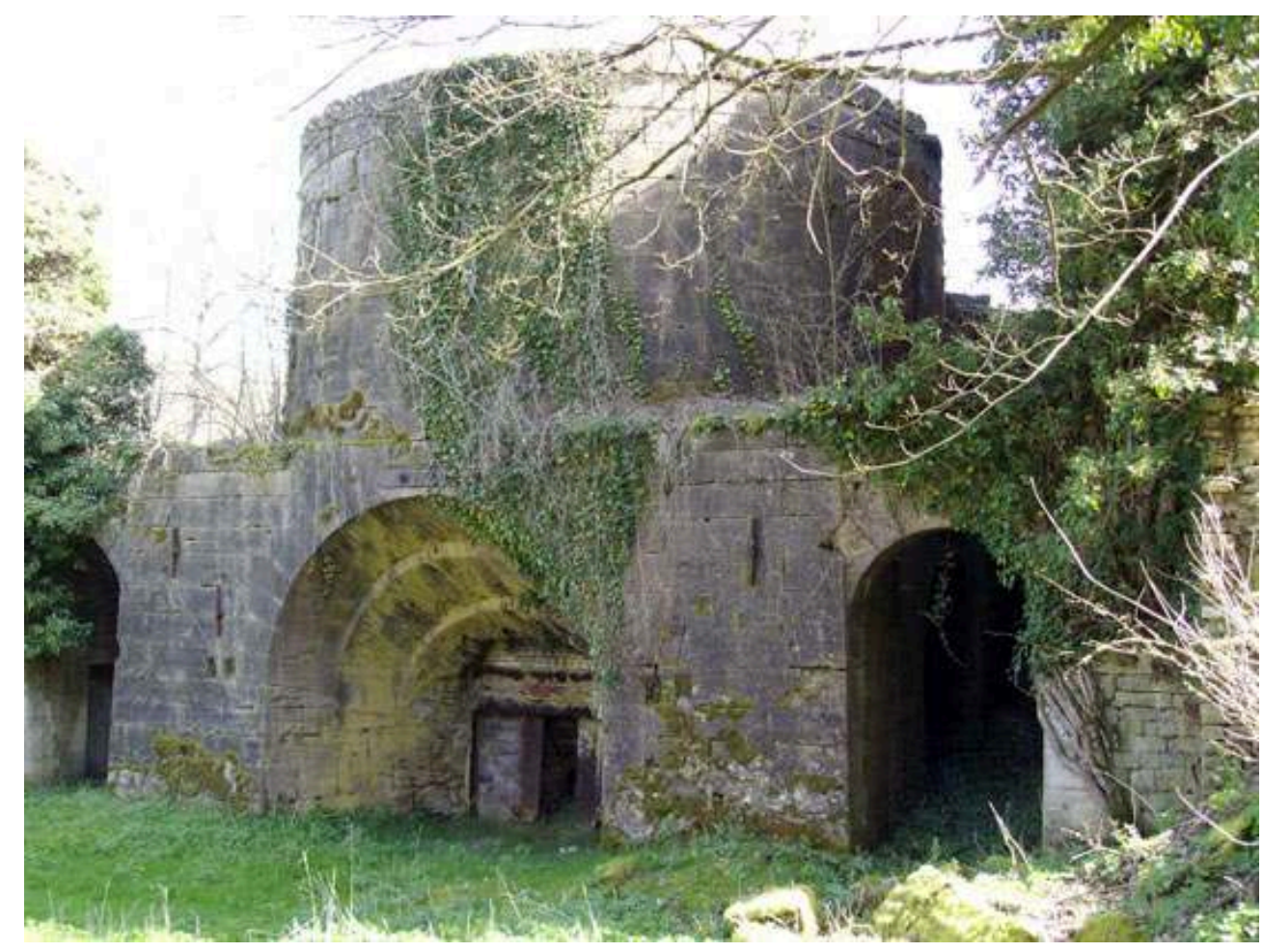

Photo : Edelblutte, 2011

Isolé dans une vallée mal reliée aux grands axes régionaux, ce haut-fourneau construit autour de 1830, sur un site où le fer était produit dans une forge depuis le début du XVème siècle, a été abandonné définitivement en 1885. Il est classique d'un passage progressif, mais avorté, de la protoindustrie à l'industrie. Le site, qui avait pratiquement disparu sous la végétation, est classé monument historique depuis 1996. II a été depuis dégagé et est accessible.

Ce lent endormissement favorise l'oubli de la friche industrielle et certainement pas sa valorisation patrimoniale : ruines cachées dans la forêt, vestiges de fondations devenus terrains vagues ou encore traces ténues d'aménagements indirects (barrages et seuils en partie contournés, canaux d'alimentation à-demi comblés...), sortent peu à peu de la mémoire locale et perdent leur caractère industriel. Cet oubli est encore favorisé par la petite taille de ces sites anciens, souvent abandonnés avant la vague de concentration de la seconde révolution industrielle.

Inscrite dans le mouvement d'inflation patrimoniale de l'après Trente Glorieuses, la redécouverte de ces sites est donc souvent récente et s'apparente à un travail d'archéologue, puisqu'il s'agit souvent de ruines, voire seulement de fondations. L'expression «archéologie industrielle» précède d'ailleurs celle de patrimoine 
industriel et désigne encore, au Royaume-Uni (industrial arachaelogy), ce même patrimoine, bien qu'elle soit considérée en France comme réductrice.

L'abandon et l'oubli fréquents du patrimoine industriel en milieu rural illustrent aussi le manque d'enjeu et de moyens pour traiter la friche, ce qui, paradoxalement, peut favoriser une redécouverte ultérieure de celle-ci :

- le manque d'enjeu conduit à une préservation par défaut du site industriel. En effet, le site abandonné est préservé de la démolition rapide qui affecte souvent, sous la pression foncière, les sites industriels urbains. Certes il n'est pas entretenu et se dégrade, mais cette configuration peut, paradoxalement, préserver plus longuement des vestiges industriels et, une fois passée la phase d'abandon et d'oubli, permettre leur réinvestissement patrimonial ;

- le manque de moyens retarde évidemment le traitement des friches industrielles, même petites. Par exemple, d'éventuelles pollutions, même mineures, figent la situation plus longtemps, et permettent finalement, comme dans le cas illustré par la photo 3 , de dépasser la phase d'oubli et de négation de l'histoire industrielle qui, souvent en zone urbaine, amène des destructions radicales.

Ce phénomène d'oubli et d'abandon peut aussi affecter certaines villes-usines enclavées, isolées et ainsi sans espoir de rebond après la fermeture de l'usine-mère. Non rurales à leur apogée, par la concentration de population qu'elles impliquaient, elles se ruralisent peu à peu en perdant leurs habitants, voire leur caractère urbain par la destruction des cités ouvrières inhabitées (encadré 2). Le paysage de ces anciens isolats industrialo-urbains perd donc progressivement sa spécificité industrielle et urbaine qui s'efface derrière la végétation de ce qui ressemble de plus en plus, à première vue, à un village. Celui-ci conserve en réalité de nombreuses traces de l'épopée industrielle qui l'a créé et ce patrimoine peut être un élément de distinction par rapport aux villages voisins et un socle pour une éventuelle revalorisation.

Encadré 2 : La Verrerie-de-Portieux (Vosges), une ancienne ville-usine en voie de ruralisation

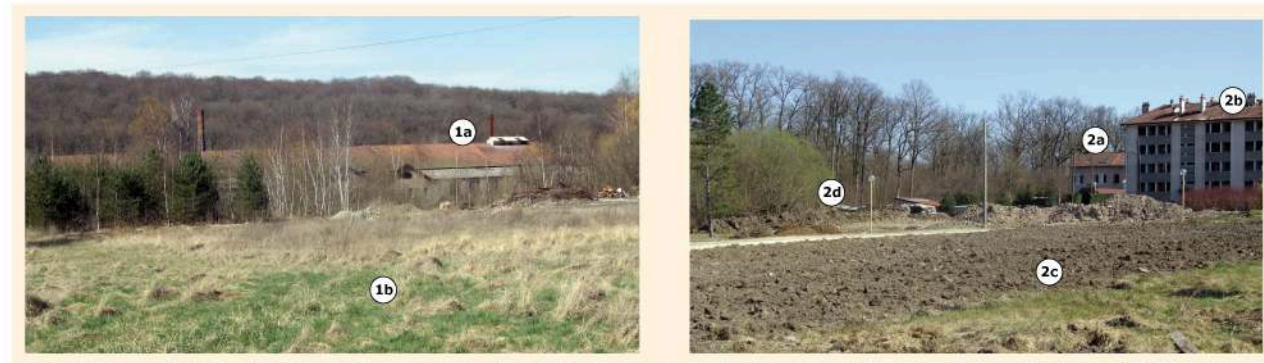

Fondée au tout début du XVIIİ̀me siècle, la Verrerie-de-Portieux atteint, à son apogée au début du XXème siècle, plus de 2000 habitants.. pour tomber autour de 400 en 2012. L'usine, qui a motivé la naissance de cette ville-usine très complète car assez isolée au milieu d'une forêt source d'énergie autrefois essentielle pour la fabrication du verre, emploie en 2012 moins de 10 personnes (plus de 800 au début du XXème siècle) et finit par fermer à la fin de l'année. Le site industriel ne comporte plus qu'une seule halle (1a), entourée de friches nues et forestières (1b).

Depuis les années 1980, la population déserte les collectifs des années 1960 qui avaient été construits à la place de casernes ouvrières jugées insalubres et dont il ne reste que de rares exemplaires (2a). L'ancienne ville-usine, dans laquelle 6 collectifs sur 12 sont en cours de destruction (2b) en 2012, est ainsi encours de ruralsation, avec de larges vides a la place des inmeubles d forestière $(2 \mathrm{~d})$.

source : Edelblutte (2000) photos: Edelblutte, 2012

Ce glissement de l'urbain au rural reste néanmoins exceptionnel en Europe occidentale ${ }^{3}$ et peut être considéré comme l'aboutissement ultime du phénomène des villes rétrécissantes (Chalard, 2007; Fol \& Cunningham-Sabot, 2010; Roth, 2011), ces dernières étant souvent d'anciennes villes-usines ayant perdu leur usine-mère. 
31 Ainsi, contrastant avec ce qui se passe dans les espaces urbains, le potentiel patrimonial industriel dans les espaces ruraux est-il caractérisé par : espaces ruraux, mais il s'en différencie, dans le second cas, par la lenteur de la réappropriation des sites et territoires abandonnés par l'industrie. De plus, cette réappropriation est en général beaucoup plus ponctuelle que dans les espaces urbains, où les friches sont traitées dans une perspective plus globale dans le cadre de grandes opérations de renouveau urbain portées par la thématique aujourd'hui incontournable du développement durable (Lamard \& Vitoux - dir., 2006 ; Gasnier \& Lamard - dir., 2007 ; Veschambre, 2008). Néanmoins, des actions patrimoniales d'ampleur peuvent être menées dans les espaces ruraux, notamment lorsque l'industrie est une composante essentielle de l'identité du territoire en question.

\section{A. Négations, mises en attente et actions ponctuelles}

Ce patrimoine industriel quelque peu oublié connaît des fortunes diverses. Si ce patrimoine est souvent oublié, voire nié (encadré 3), il est aussi, dans des territoires ruraux aux moyens souvent limités, fréquemment et délibérément mis en attente, c'est-à-dire que les divers acteurs sont conscients de l'intérêt de ce patrimoine mais ne peuvent le mettre en valeur. Cette mise en attente prolonge l'abandon de fait, même si l'oubli est réparé. 
Encadré 3 : l'oubli du patrimoine industriel dans le village-usine de Gironcourt-sur-Vraine, Vosges
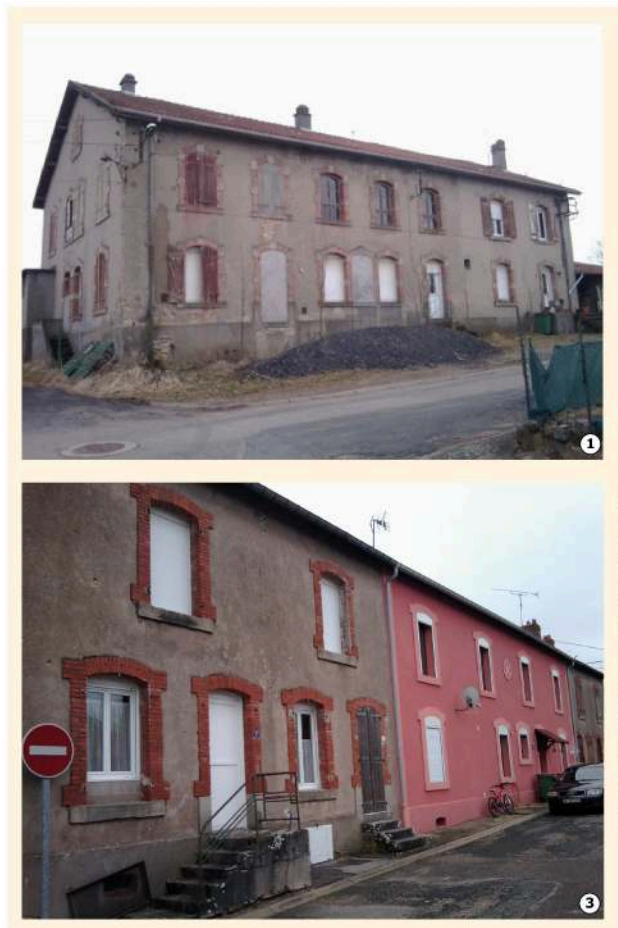

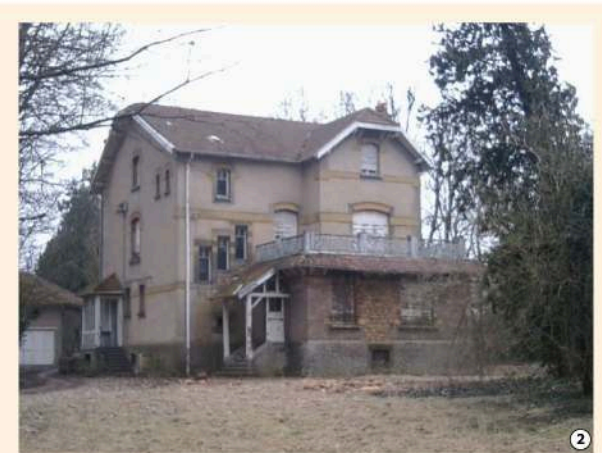

L'usine qui a donné naissance au village-usine de Gironcourt-sur-Vraine appartient en 2012 au groupe américain Owens Illinois (OI) qui y emploie encore environ 280 personnes (contre 715 en 1989). Toujours village-usine qu'elle avait créé. Les cités ouvrières ont pour la plupart été revendues à leurs cccupants, devenus propriétaires. parcles appartiennent cependant toujours à l'entreprise un désintérêt manifeste pour une éventuelle politique patrimoniale, car " c'est une usine ici . l'important c'est la production ". Plusieurs bâtiments autrefois liés à l'industrie ont été détruits, dont la maison du directeur (rasée pour construire une salle des fêtes) ou sont abandonnés (ancienne école (1), ancienne maison du sous-directeur (2)). Les cités ouvrières sont de plus en plus personnalisées sans homogénéité (3) par leurs propriétaires. La municipalité n'intervient pas et son unique projet (non réalisé) dans le domaine du patrimoine industriel a été d'envisager la réalisation d'une petite exposition sur ce thème en mairie.

Sources : entretiens du 29 février 2012 avec un cadre de l'entreprise OI ; avec M. Langrognet, ancien employé de la verrerie ; avec M. Huraux, conseiller municipal et employé de la verrerie

37 La mise en attente implique d'abord une connaissance de l'ancien site industriel pour pouvoir en envisager une éventuelle reconversion/réutilisation impliquant un volet patrimonial. C'est ce qu'a réalisé la Communauté de Communes du Pays de Revignysur-Ornain (COPARY), dans le département de la Meuse, à propos de Maison-du-Val, un ancien village-usine (encadré 4). 


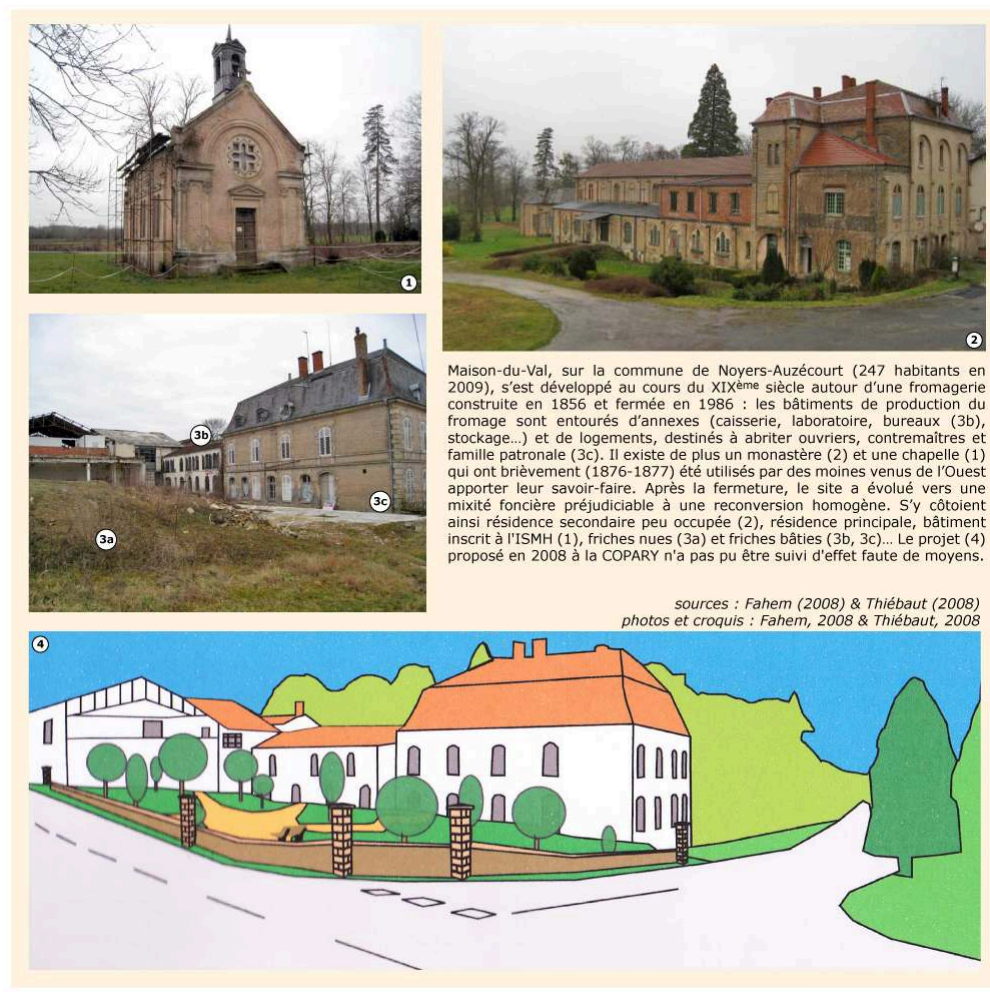

En 2008, la COPARY finance une petite étude (Fahem, 2008; Thiébaut, 2008) pour déterminer des pistes de réutilisation de la demeure patronale, des bureaux et du parc attenant qui sont alors mis en vente par leur propriétaire, constituant une opportunité foncière pour les collectivités locales. Cette action illustre la prise de conscience patrimoniale des autorités face à ce patrimoine industriel exceptionnel, mais largement abandonné. Les propositions de l'étude, qui tendaient vers une maison de retraite ou un gîte rural entouré d'un parc, n'ont pas été suivies d'un effet direct, mais de nouveaux propriétaires privés ont entrepris, dans une démarche assez proche de ce qui avait été proposé, la transformation de cette demeure en chambre d'hôtes ${ }^{4}$. La complexité du dossier, qui mêle divers types de propriétés et de patrimoines, mais aussi les faibles moyens des opérateurs, n'ont pas pu conduire à un traitement global du site et aboutissent finalement à une mise en attente, certes consciente du potentiel patrimonial du site, mais ne garantissant pas sa survie par une réoccupation pérenne.

Premier pas vers une reconnaissance patrimoniale, la mise en attente après étude et inventaire est fréquente dans des territoires ruraux au faible dynamisme démographique et économique. Dans des espaces ruraux au potentiel de redéveloppement plus avéré (plus accessible, avec des attraits touristiques, proches des grandes villes ou des grands axes), des actions plus concrètes de valorisation du patrimoine industriel deviennent possibles, mais ce sont plus souvent des actions ponctuelles que des actions d'envergure et de grande ampleur. Issues d'initiatives locales et parfois même privées, elles aboutissent à la réhabilitation et la mise en valeur, plus ou moins complète d'anciens sites/bâtiments industriels.

Commune rurbaine de Meurthe-et-Moselle bien reliée à Nancy et Épinal par une voie rapide, Bainville-aux-Miroirs (354 habitants en 2009), a mené un début de 
réhabilitation et de mise en valeur d'une ancienne clouterie fermée depuis 1990 (encadré 5).

Encadré 5 : Un début d'opération industrialo-patrimoniale à Bainville-aux-Miroirs (Meurthe-etMoselle)

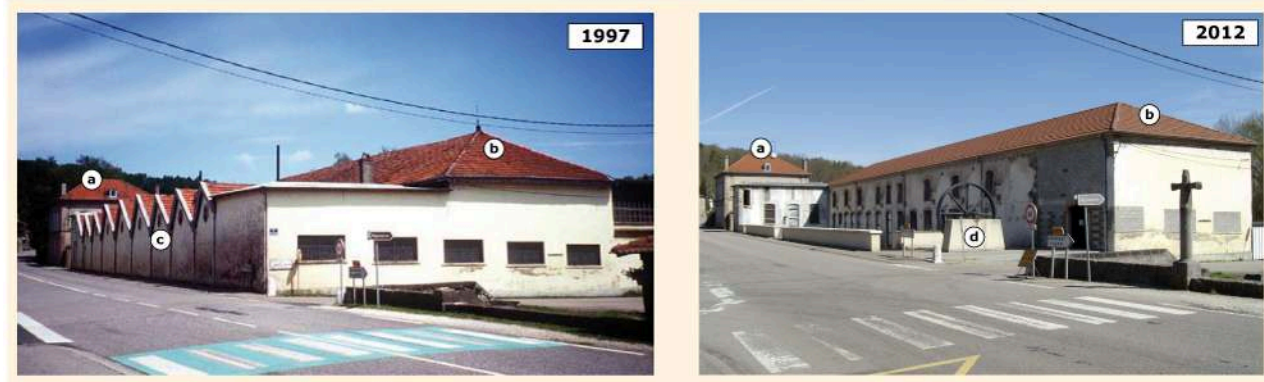

Composée de deux bâtiments de production, d'annexes de stockage et de la maison patronale (a), quelque peu noyée dans le bâti industrie , la clouterie de Bainville-aux-Miroirs a été fondée en 1855. Loperation patrimoniale, effectuée en 2006, a consiste a dégager le bâtiment plus ancien (b) et le plus intéressant au niveau architectural, en détruisant le bâtiment au toit à sheds (c), plus récent (années 1880). Consi-

déré comme plus banal, il gênait, de plus, la circulation au carrefour attenant. courroies et poulies, l'énergie hydraulique aux machines, apporte à l'observateur une perception nouvelle et beaucoup plus positive de ce patrimoine industriel.

L'aboutissement du projet, qui s'oriente vers une réhabilitation mixte comprenant des logements, des bureaux, un petit musée de la Seconde guerre mondiale et de la clouterie incluant quelques machines, voire un transfert de l'école, reste suspendu à l'obtention de financements dans un contexte difficile ${ }^{5}$. Néanmoins, la volonté de prendre en compte cet ancien site industriel, inactif depuis 1990, dans une action de développement local, illustre une prise de conscience incontestable de l'intérêt du patrimoine industriel dans cette commune. Si elle n'est pas née de l'industrie et n'a été que marginalement marquée par elle, Bainville-aux-Miroirs a donc intégré cette marque industrielle dans sa mémoire et son identité. Mieux encore, elle l'utilise comme un atout de développement, la distinguant ainsi de ses voisines plus exclusivement rurales. Les collectivités locales sont donc en première ligne de ces actions ponctuelles en zone rurale, mais elles peuvent être, dans certains contextes particuliers, largement secondées, voire dépassées par des initiatives privées et/ou associatives.

Dans le département de l'Ardèche, le travail de la soie, essentiellement par le moulinage qui consiste à retordre les fils de soie pour les rendre plus résistants, a généré à partir de la fin du XVIII ${ }^{\text {ème }}$ siècle mais surtout au XIX ${ }^{\text {ème }}$ siècle, des chapelets

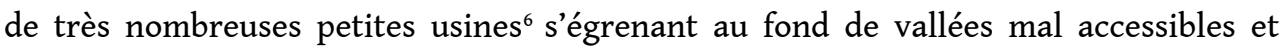
étroites. La qualité des eaux non calcaires, la culture d'entreprise liée au protestantisme, la présence d'une main d'œuvre inoccupée l'hiver pendant le maximum démographique rural du XIX ${ }^{\text {ème }}$ siècle, la proximité de Lyon, centre de tissage de la soie (Canuts), a présidé à ce système industriel. Les moulinages, grosses bâtisses de pierre, allongées, à étages et aux larges ouvertures marquent le paysage des vallées ardéchoises avant leur déclin à partir de la première moitié du XX ${ }^{\text {ème }}$ siècle. Face aux évolutions techniques et économiques, ces lourdes bâtisses semblent, durant les années 1950 à 1980, vouées à un abandon inexorable et donc un lent effacement par leur dégradation, la démolition coûtant souvent trop cher pour des communes rurales anémiées.

Or, au début du XXI ${ }^{\text {ème }}$ siècle, ces anciens moulinages sont, au contraire toujours debout et sont devenus un élément essentiel du patrimoine ardéchois au sens large, pas seulement industriel. En effet, dans un contexte de développement du tourisme rural et 
dans un département, certes difficile d'accès, mais au potentiel touristique énorme, ces bâtiments de taille réduite, bénéficiant de plus d'un accès à l'eau par barrage et ancien canal usinier, ont d'abord pu devenir d'excellents hébergements touristiques (gîtes, auberges, chambres d'hôtes, résidences secondaires). Ils ont pu aussi servir de lieux pour des artistes, des artisans ou des petits producteurs arrivés dans un contexte de repeuplement d'un département phare pour les mouvements néo-ruraux et/ou alternatifs de la seconde moitié du XXème siècle (encadré 6).

Encadré 6 : Les moulinages d'Ardèche, une valorisation variée pour un patrimoine industrialo-rural exceptionnel

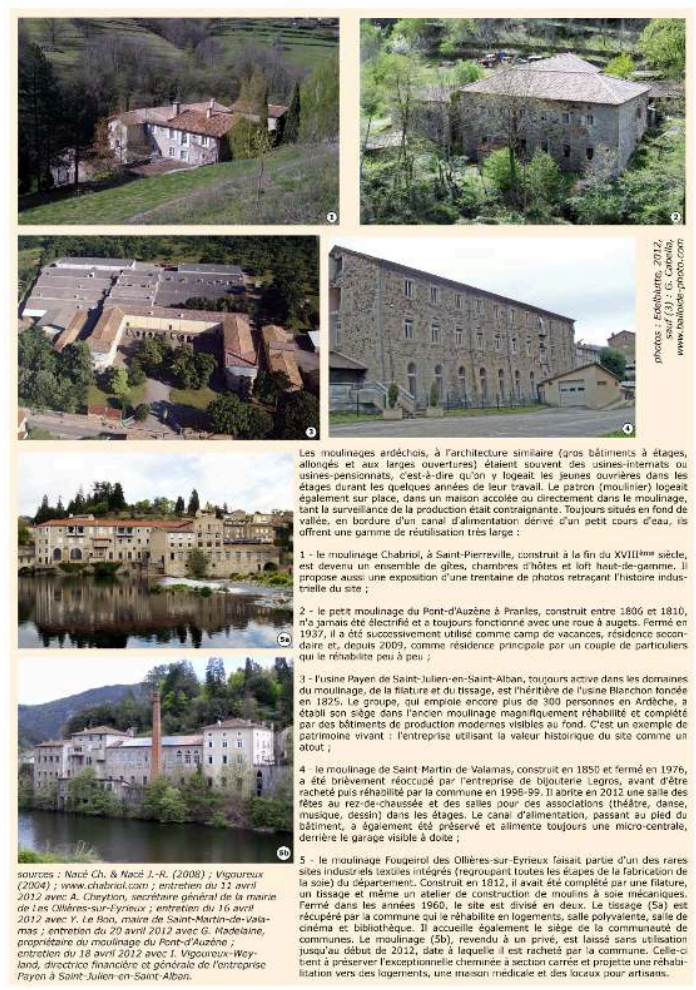

Inscrites dans ce mouvement, certaines de ces initiatives sont particulièrement spectaculaires. À Saint-Pierreville, une petite usine, déclinante dès avant la Seconde guerre mondiale et finalement abandonnée dans les années 1960, abritait une filature de laine et un moulinage de la soie. Sa dizaine d'employés travaillait essentiellement pour des clients locaux (Barras, 2006). Récupéré par un groupe alternatif en 1972, le bâtiment devient le siège d'Ardelaine, Société Coopérative et Participative (SCOP) travaillant la laine d'abord dans une perspective de redéveloppement territorial et local et non dans un objectif commercial. Il s'agit, dans un premier temps, de récréer la filière de la laine (de l'élevage au circuit commercial), puis de restaurer le patrimoine du site tout en créant des emplois et donc de favoriser le développement local.

La culture alternative dans laquelle s'inscrivent les fondateurs, mêlant avec succès tissus associatif, social et économique, leur a permis de développer le site et même de l'agrandir, avec la construction d'un musée et d'un restaurant, complétant la filature ${ }^{7}$. Le site offre donc une image composite, avec la vieille filature entourée en 2012 de plusieurs bâtiments plus récents ou reconstitués sur place (photo 4). 
Photo 4 : Le site d'Ardelaine, un patrimoine industriel réinventé à Saint-Pierreville, Ardèche

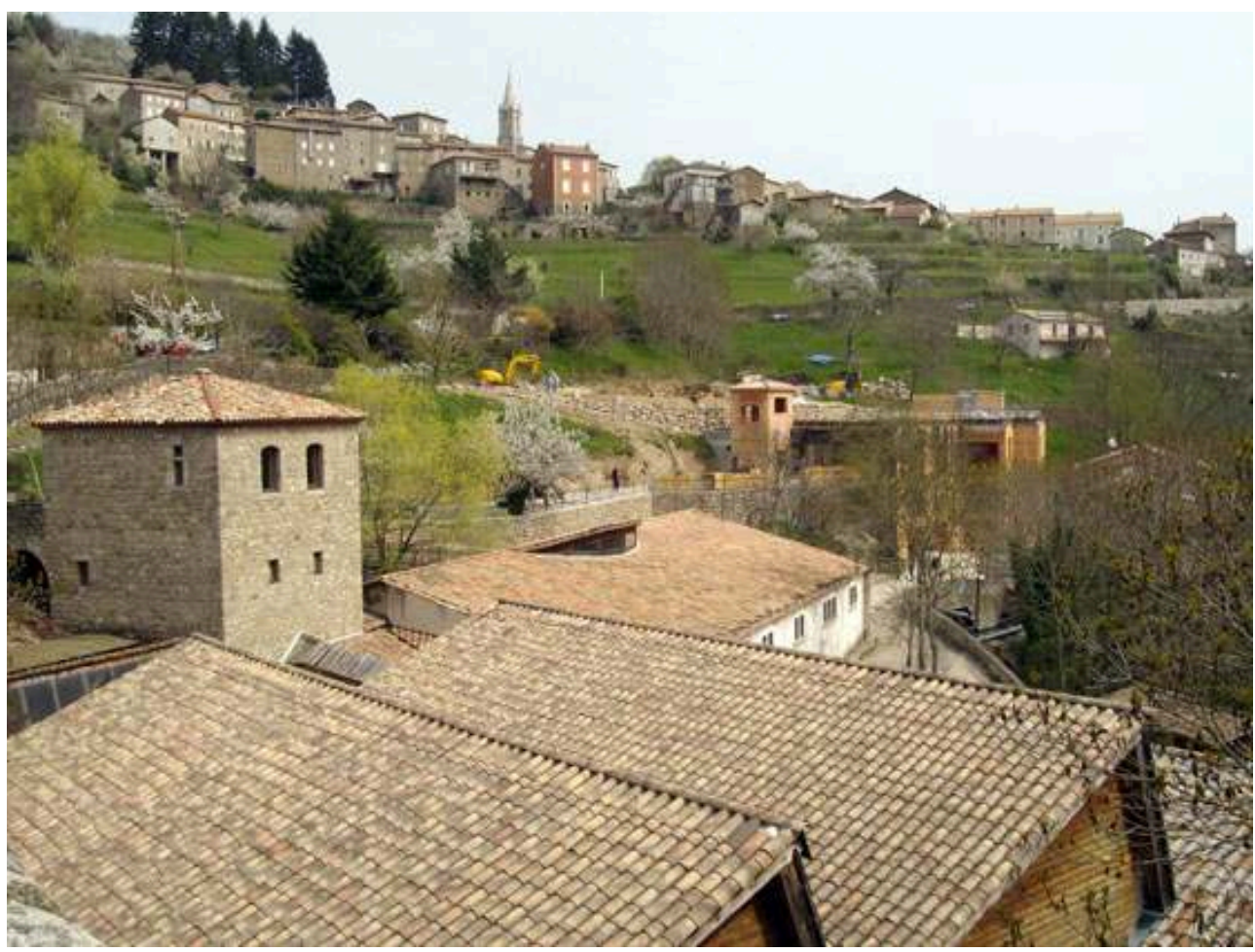

Photo : Edelblutte, 2010

Au pied du village de Saint-Pierreville, l'ancienne filature est cachée par un bosquet (à droite). Elle a été entourée par des bâtiments récents abritant musée et activité de production, comme, au premier plan, un bâtiment à sheds dont la charpente a été récupérée à Lavelanet, en Ariège. Au fond, le chantier est celui du restaurant, complétant et diversifiant en 2012 l'activité du site.

Si l'image industrielle du site est quelque peu brouillée par ces nouvelles constructions, la combinaison entre le respect et la valorisation du passé industriel et l'activité industrialo-touristique récente en fait une sorte de patrimoine vivant qui regroupe un patrimoine matériel actif et un patrimoine immatériel, c'est-à-dire les savoir-faire et la culture industrielle locale. Cela est particulièrement valorisant pour ce territoire très enclavé.

47 Ces premières initiatives, associatives ou privées, ont montré l'exemple aux communes qui ont ensuite réinvesti les anciens moulinages pour des usages mixtes, allant des logements sociaux aux salles de fêtes en passant par des bibliothèques, des salles polyvalentes, des musées, des locaux administratifs, etc. (encadré 6). Le patrimoine industriel ardéchois est ainsi clairement reconnu apportant "une vision plus réaliste à un département qui ne saurait se réduire à un pseudo-conservatoire des traditions rurales" (Nacé Ch. \& Nacé J.-R., 2008, p. 284).

48 Les actions présentées dans cette partie restent cependant relativement ponctuelles, en rapport avec la fréquente dispersion et la taille souvent modeste de ce petit patrimoine industriel en zone rurale; ainsi, même en Ardèche, de nombreux sites restent à l'abandon et s'effacent peu à peu du paysage. Ces actions ne sont quasiment jamais comparables aux grosses opérations de renouveau urbain intégrant la valorisation du patrimoine industriel et concernant, en ville et à la charnière des $X^{\text {ème }}$ et XXI ${ }^{\text {ème }}$ siècles, les faubourgs industriels ou industrialo-portuaires délaissés. 


\section{B. Des actions d'envergure plus rares}

49 patrimoniale concernant directement ou indirectement l'industrie ou ses annexes. Elles
sont seulement beaucoup plus rares qu'en ville et sont toujours liées à des contextes ou
à des héritages bien particuliers.
Cela concerne d'abord d'anciens sites industriels exceptionnels, comme la saline royale
d'Arc-et-Senans, en l'occurrence un site proto-industriel (photo 5). Photo 5 : La saline royale d'Arc-et-Senans, Franche-Comté

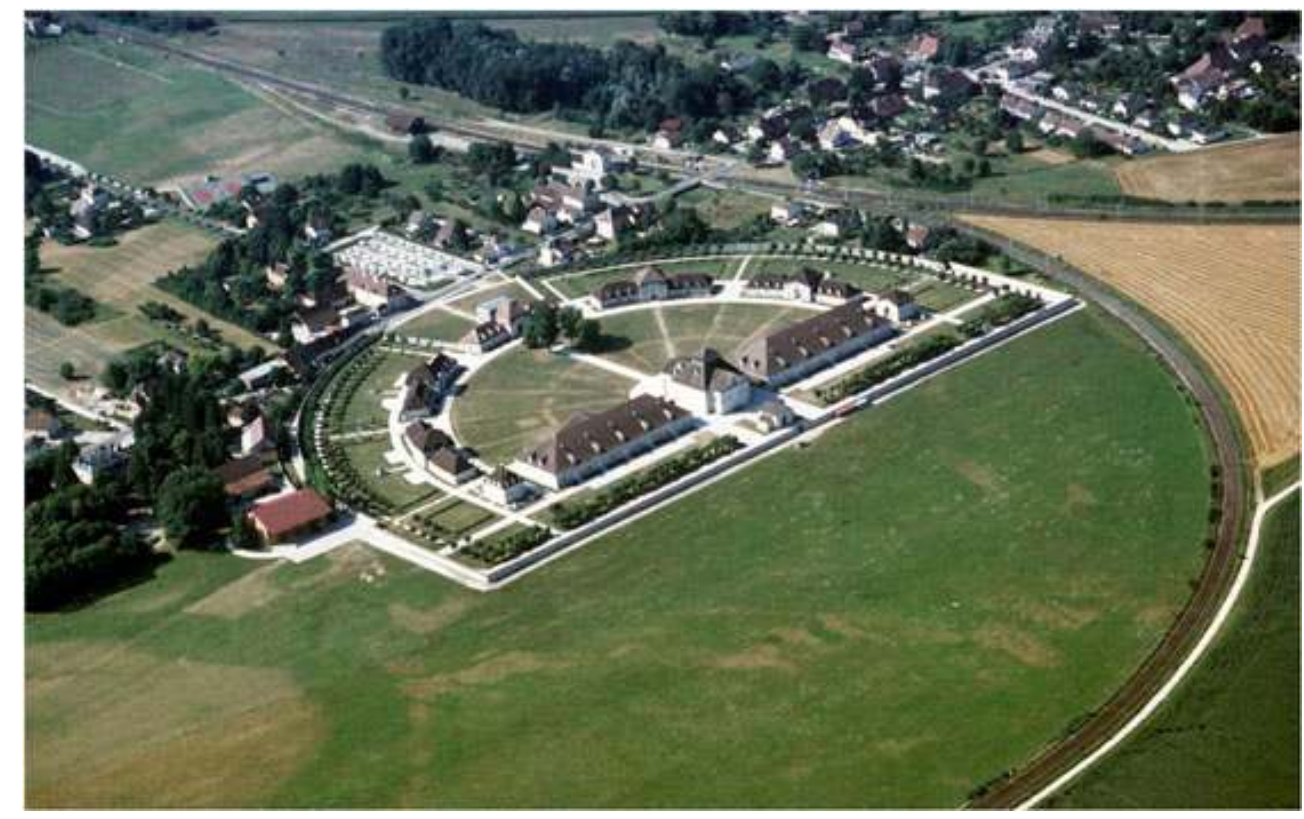

Photo : Humbert, Renard-Grandmontagne, 1998

Ce magnifique ensemble est construit en 1779 non loin des sources salées de Salins et surtout à côté de l'immense forêt de Chaux, dont le bois est indispensable pour chauffer les poêles d'évaporation du sel. Le bâtiment central abrite la direction et est entouré des deux halles aux sels. Des bâtiments annexes (écuries, entrepôts...) complètent un ensemble à l'allure monumentale marquée.

Dans ce cas, la valeur architecturale de la manufacture, comme sa valeur d'exemple en tant qu'utopie proto-industrielle, a motivé son classement au titre de monument historique, dès 1926, puis son inscription en 1982 au patrimoine mondial de l'UNESCO. La saline royale constitue donc aujourd'hui un exceptionnel isolat industrialopatrimonial dans un espace par ailleurs très rural.

52 Parallèlement, et à une échelle inférieure, d'importantes actions de protection patrimoniale peuvent concerner des villages-usines particulièrement anciens, complets, cohérents et bien préservés. C'est cette cohérence et cette préservation, plus que les qualités architecturales propres, qui motivent la reconnaissance, la protection et la mise en valeur de ce patrimoine industriel dans son ensemble, comme le montrent les deux exemples suivants :

53 - le village de Blanchland au Royaume-Uni (Northumberland, Angleterre), comporte plusieurs dizaines de bâtiments classés grade II, un grade II* et quatre classés grade I (www.britishlistedbuildings.co.uk) ${ }^{8}$; la quasi-totalité du village, ainsi que quelques fermes et hameaux voisins, est en fait inscrite et protégée. Il s'agit d'un ancien village 
minier dont la population, qui atteignait environ 700 habitants au XIX ${ }^{\text {ème }}$ siècle, était occupée à extraire le plomb dans plusieurs mines autour du village. Développé sur une ancienne abbaye médiévale, il présente ainsi un caractère exceptionnellement homogène ; de plus, son isolement au cœur de la chaîne Pennine, dans un secteur de moyenne montagne océanique aux conditions de vie difficiles, l'a préservé d'évolutions

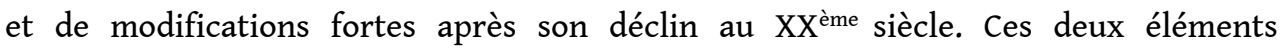
(homogénéité et préservation) ont motivé sa protection (encadré 7);

Encadré 7 : Blanchland (Royaume-Uni), un ancien village minier protégé

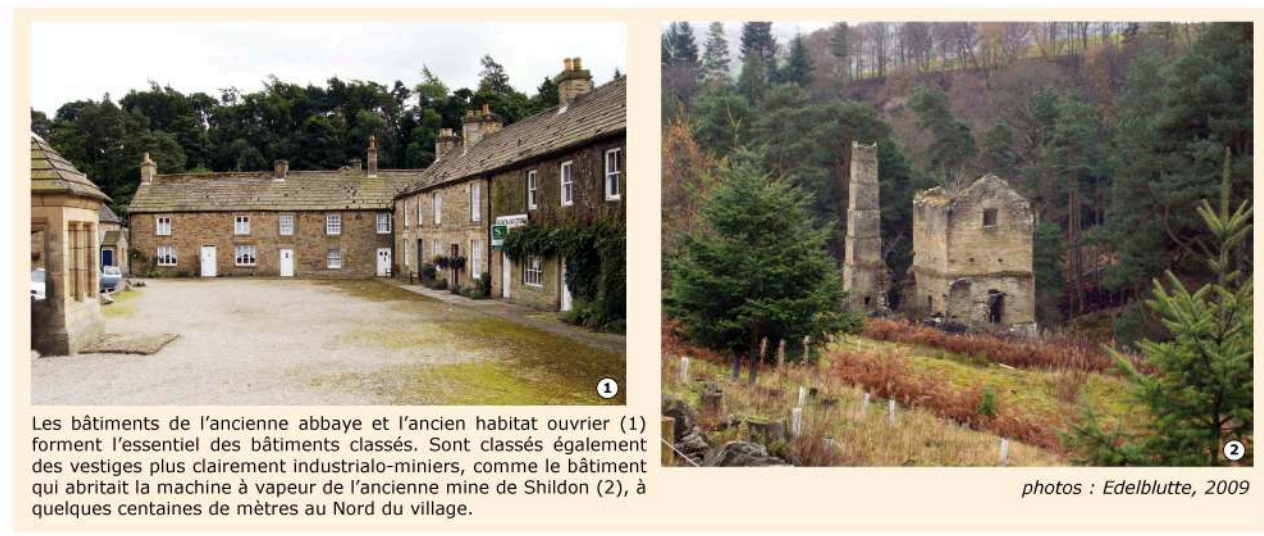

à Villeneuvette (encadré 8), dans l'Hérault, une manufacture de draps fins de laine est autorisée par le pouvoir royal en 1677. Construite de la fin du XVII ${ }^{m e}$ au début du XVIII ${ }^{\text {ème }}$ siècles, elle comporte des bâtiments de production, des cités ouvrières, des bâtiments économiques et sociaux, formant un village-usine proto-industriel, puis industriel, particulièrement complet, avant que l'usine ne ferme en 1954, après presque 300 ans d'existence (Belhoste \& Smith, 1997). Cet ensemble rural assez isolé a été depuis préservé de toute modification majeure, mais pas d'une lente dégradation qui affecte surtout les anciens bâtiments de production, malgré l'inscription de plusieurs bâtiments à l'Inventaire Supplémentaire des Monument Historiques (ISMH) et la création d'une Zone de Protection du Patrimoine Architectural Urbain et Paysager (ZPPAUP) en 1995. Les habitations sont par contre assez bien entretenues par leurs occupants devenus propriétaires. En 1969, ceux-ci ont érigé l'ensemble en copropriété pour conserver la cohérence du village-usine (www.les-amis-de-villeneuvette.fr). Cependant, c'est surtout par l'activité associative, aidée du département qui a acheté l'ancienne usine et les ouvrages hydrauliques, que l'ensemble est peu à peu restauré et entretenu, conservant ici un village-usine d'origine proto-industrielle, d'une exceptionnelle cohérence en milieu rural. 
Encadré 8 : Villeneuvette (Hérault), un village-usine proto-industriel en cours de préservation
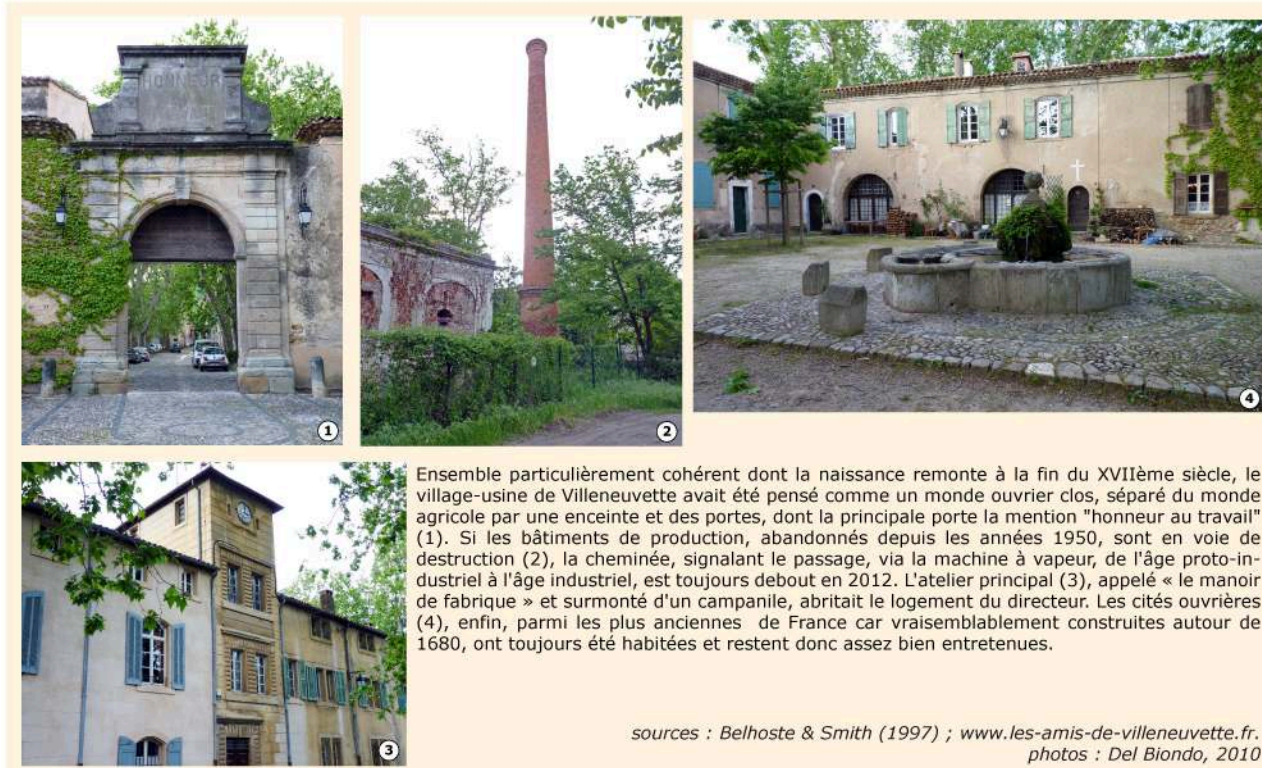

Ensemble particulièrement cohérent dont la naissance remonte à la fin du XVIrème siècle, le village-usine de Villeneuvette avait été pensé comme un monde ouvrier clos, séparé du monde agricole par une enceinte et des portes, dont la principale porte la mention "honneur au travail" (1). Si les bátiments de production, abandonnes depuis les années 1950 , sont en voie de dustriel à l'âge industriel est toujours debout an 2012 . L'atelier principal (3), appelé « le mano dustriel a lage industriel, est toujours debout en 2012 . Latelier principal (3), appelé « le manoir (4), enfin, parmi les plus anciennes de France car vraisemblablement construites autour de 1680 , ont toujours été habitées et restent donc assez bien entretenues.

sources : Belhoste \& Smith (1997); www.les-amis-de-villeneuvette.fr. photos : Del Biondo, 2010 retrouve les éléments déterminants pour une protection d'importance en zone rurale : la cohérence du bâti industriel, l'ancienneté, avec des origines proto-industrielles dans les deux cas, mais aussi un certain isolement qui les a protégés de fortes évolutions au $\mathrm{XX}^{\text {ème }}$ siècle. les actions de valorisation du patrimoine industriel peuvent encore s'élargir. Il s'agit alors de préserver non seulement le patrimoine industriel physique (bâtiments, paysages) mais aussi et surtout la culture industrielle du territoire, considérée ainsi comme un patrimoine essentiel au fonctionnement économique du territoire et au maintien de ses emplois industriels. La culture industrielle peut-être définie comme " l'ensemble des savoir-faire et des valeurs éthiques et esthétiques qui se tissent autour du processus de production, de l'acte productif et du produit lui même » (Daviet, 2005, p. 84). Elle se constitue autour d'une communauté industrielle regroupant «ceux qui partagent la même foi dans le travail et la profession d'acteurs de l'industrie " (Daviet, op. cit., ci-dessus).

L'action de l'Arche des Métiers dans les Boutières (Ardèche), territoire rural sans délimitation officielle, mais que l'on fait en général correspondre aux deux cantons du Cheylard et de Saint-Martin-de-Valamas, est révélatrice de cette politique. Dans ces deux cantons montagnards de moins de 10000 habitants, très enclavés, le développement industriel a néanmoins eu lieu à la fois en raison de la qualité de l'eau qui a favorisé le textile, vite relayé, dès le XIX ${ }^{\text {ème }}$ siècle, par une spécialité originale, la bijouterie. Celle-ci est attirée là par l'abondance de la main d'œuvre (au temps du maximum démographique rural) et par sa qualité. Ne manipulant que des objets facilement transportables, cette activité est peu pénalisée par l'enclavement. Textile et bijouterie sont ensuite peu à peu renforcés par le développement de la construction mécanique et quelques autres spécialités, le plus souvent effectuées dans des Petites et Moyennes Industries (PMI), rapprochant ce territoire de l'idée de district industriel (Maisonniac, 2000). 
répond en rien aux criteres actuels de localisation industrielle melant accessibilite et crien aux cres actuels de localisation industrielle mêlant accessibilité et coût réduit de la main d'œuvre? Deux entretiens, l'un réalisé avec Ch. Féroussier, directeur technique de l'Arche des Métiers du Cheylard et D. Bosc, chargée de la communication, et l'autre, réalisé avec le Dr. J. Chabal maire de la commune du Cheylard et conseiller général d'Ardèche ${ }^{9}$, mettent en lumière l'existence d'une culture industrielle pour expliquer cette pérennité industrielle sur ce territoire. Les deux acteurs soulignent, à propos de leur territoire et de sa population, «la fierté d'appartenir à l'entreprise, la culture de l'entreprise et l'aspect familial dans les relations entre les dirigeants et leurs salariés ». Cette culture, selon eux, se développe d'ailleurs plus facilement dans un territoire rural et enclavé qu'en milieu urbain car " cet enclavement, présenté comme un handicap en termes d'accès, peut aussi être vu comme un avantage, car il a permis le développement, dans un milieu familial, d'un esprit de travail, de prise de responsabilité et de solidarité». Enfin, pour eux, "l'industrie doit être certes développée, mais elle est basée sur lêtre humain et sa culture ». C'est ainsi cette culture industrielle qui est un patrimoine, plus que les usines et les paysages.

Cette conception de l'industrialisation du territoire et surtout la volonté de la rendre pérenne (et donc de maintenir les emplois), a conduit à la fondation, en 2005, de l'Arche des Métiers. Cette structure, lien entre les industriels, la population et les extérieurs, a pour but de promouvoir le territoire et son industrie, pas seulement en étant une vitrine de l'industrie des Boutières, mais aussi en impliquant la population, notamment les jeunes, à la fois dans l'histoire industrielle du territoire et vers son avenir. Une exposition permanente, intitulée "le génie des Boutières " et présentée au siège de l'Arche des Métiers (photo 6), illustre bien les liens entre culture, industrie et territoire, dans un enracinement cité par Ch. Féroussier à propos des industriels eux-mêmes qui ne souhaitent pas quitter le territoire. 


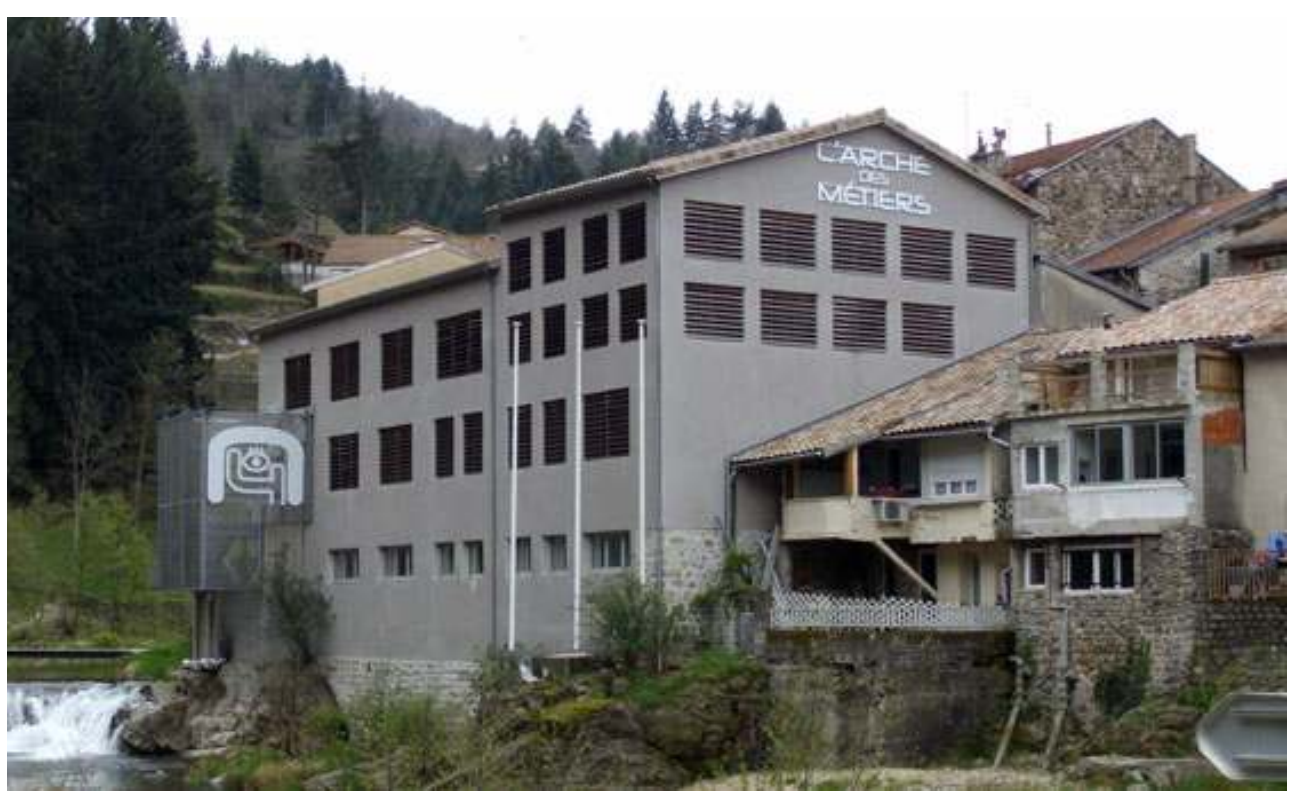

Photo : Edelblutte, 2012

L'Arche des Métiers manifeste par son siège même son attachement à la culture et au patrimoine industriel des Boutières. II s'agit en effet d'une ancienne tannerie, bien repérable aux larges ouvertures équipées de claies qui permettaient à l'air de circuler dans le bâtiment pour le séchage des peaux. Enchâssée dans le bâti du Cheylard, elle domine la Dorne dont elle utilisait autrefois les eaux comme force motrice.

61 Cet exemple des Boutières, territoire rural où l'enracinement est présenté comme un gage de pérennité pour le tissu industriel, éclaire la notion de patrimoine d'un jour beaucoup plus large que l'acception habituelle. Il permet aussi de comprendre que ce petit patrimoine industriel rural, souvent présenté comme un «intrus » en milieu rural, lui est en fait consubstantiellement lié, peut-être plus que dans beaucoup de villes où l'aventure industrielle, si elle a été parfois brutale et spectaculaire, a finalement été plus éphémère.

\section{Conclusion}

$62 \mathrm{Au}$ terme de cette étude et des quelques exemples présentés, il apparaît que le patrimoine industriel en milieu rural ne se résume ni à de rares implantations protoindustrielles spectaculaires et évidemment préservées, comme Arc-et-Senans, ni finalement à un ensemble de petites traces ténues et peu mises en valeur. La variété est en fait très grande, mais des éléments spécifiques distinguent ce patrimoine industriel rural du patrimoine industriel urbain.

63 Le milieu rural est un conservatoire de formes industrielles anciennes, beaucoup plus que la ville où les changements sont en général plus rapides et plus brusques, notamment dans le domaine économique et donc industriel. Ainsi, les formes industrielles très anciennes peuvent être encore sensibles dans les campagnes, là où en ville, destructions et rénovations sont fréquentes. Le manque d'enjeu et de moyens pour faire évoluer tel ou tel site abandonné en est le principal responsable; la différence essentielle du traitement de ces sites industriels tient donc surtout à la 
lenteur des processus en milieu rural, à une certaine inertie territoriale qui n'a que rarement cours en ville.

Cette inertie (voire ce retard) dans le traitement du patrimoine industriel rural, bien qu'elle puisse être nuancée dans de nombreux cas, pose aussi la question de la nature même de ce patrimoine qui a été longtemps lié à la ville seule. En effet, l'industrie a fait naître certaines villes (les villes-usines), grandir d'autres, et a donc largement contribué à l'urbanisation des pays où elle s'est développée. C'est en ville que l'industrie est la plus visible et que la conscience patrimoniale, dans ce domaine, est née en premier, notamment face aux destructions. La notion de patrimoine industriel est donc au départ surtout façonnée et portée par des urbains; son lien avec le monde rural, pourtant plus ancien que celui qui s'est construit avec la ville, a donc souvent été sous-estimé.

Cependant, les différentes expériences présentées montrent qu'à condition d'en avoir les moyens et la volonté, le patrimoine industriel peut être un atout de redéveloppement pour le milieu rural, un point fort sur lequel des initiatives locales peuvent s'ancrer (cas d'Ardelaine). La prise de conscience que cette histoire industrielle, voire ce tissu industriel actuel (comme dans le cas des Boutières), fait partie de l'identité locale et n'est pas qu'un moyen économique de subsistance, est néanmoins essentielle pour que ce patrimoine industriel soit mis en valeur, ou tout au moins sauvegardé. Cette prise de conscience passe par les tâches immenses que constituent l'inventaire et la connaissance de ces vestiges et de ce tissu industriel dans des territoires où les moyens sont souvent faibles et plutôt tournés vers la promotion de l'agriculture ou du tourisme. Elle peut aussi contribuer à élargir l'approche du patrimoine industriel en général.

\section{BIBLIOGRAPHIE}

Barras B., 2006, Moutons rebelles. Ardelaine, la fibre du développement local, Valence, Éditions REPAS, $171 \mathrm{p}$.

Béguin F., 1995, Le paysage, Paris, Flammarion, 123 p.

Belhoste J.-F. \& Smith P. (dir.), 1997, Patrimoine industriel, 50 sites en France, Paris, Éditions du patrimoine, $128 \mathrm{p}$.

Bergeron L. \& Dorel-Ferré G., 1996, Le patrimoine industriel, un nouveau territoire, Paris, Liris, 127 p.

Chalard L., 2007, « Des villes françaises en net déclin démographique. Le cas de communes anciennement industrielles », Population et Avenir, $\mathrm{n}^{\circ}$ 683, p. 17-19.

Chevallier R., 1976, « Le paysage, palimpseste de l'histoire », Mélanges de la Casa de Velasquez, t. XII, p. 503-510.

Choay F., 1992, L'allégorie du patrimoine, Paris, Seuil, 278 p.

Daviet S., 2005, Industrie, culture, territoire, Paris, L'Harmattan, 208 p. 
Edelblutte S., 1997, « La clouterie de Bainville-aux-Miroirs (1855-1990) », Le Pays Lorrain, n4 4, Vol. 78, p. 286-289.

Edelblutte S., 2000, « La Verrerie-de-Portieux. Genèse et transformation d'un isolat industrialourbain ", Le Pays Lorrain, n4, Vol. 81, p. 257-266.

Edelblutte S., 2009a, « Paysages et territoires du patrimoine industriel au Royaume-Uni », Revue Géographique de l'Est [En ligne], vol. 48 / 1-2 | 2008, mis en ligne le 24 novembre 2009, consulté le 23 avril 2012, URL : http://rge.revues.org/index1165.html

Edelblutte S., 2009b, « Que sont devenues les villes-usines ? Réflexion à partir du cas lorrain », in Vallat C. (dir.), Dufaux F., Lehman-Frisch S. (coord.), Pérennité urbaine, ou la ville par-delà ses métamorphoses, vol. 3 : Essences, Paris, L'Harmattan, p. 137-153.

Edelblutte S., 2010a, Paysages et territoires de l'industrie en Europe : héritages et renouveaux, Paris, Ellipses, $272 \mathrm{p}$.

Edelblutte S., 2010b, « La reconversion des anciennes villes-usines européennes ou la question de la survie urbaine », Géographies - Bulletin de l'Association de Géographes Français, n³, p. 353-367.

Edelblutte S., 2012, Paysages industriels en Europe. Constructions, reconversions, patrimonialisations, Habilitation à Diriger des Recherches (dir. : S. Daviet \& M. Deshaies), Université de Lorraine, vol. $1 \& 2,186$ p. \& 408 p.

Fabriès-Verfaillie M., Stragiotti P. \& Jouve A., 2000, La France des villes : le temps des métropoles, 2 ème édition, Paris, Bréal, 337 p.

Fahem M., 2008, Projet d'aménagement et diagnostic de charte paysagère, Rapport de stage de Master 1 à la Communauté de Communes du Pays de Revigny-sur-Ornain, Nancy Université, 107 p.

Fol S. \& Cunningham-Sabot É., 2010, « Déclin urbain et Shrinking Cities : une évaluation critique des approches de la décroissance urbaine », Annales de Géographie, n 674, 4-2010, p. 359-383

Frémont A., 1976, La région, espace vécu, Presses Universitaires de France, 223 p.

Gasnier M. \& Lamard P. (dir.), 2007, Le patrimoine industriel comme vecteur de reconquête économique, Panazol, Charles Lavauzelle, 199 p.

Holz J.-M. \& Houssel J.-P., 2002, L'industrie dans la nouvelle économie mondiale, Paris, Presses Universitaires de France, $450 \mathrm{p}$.

Houssel J.-P., 1992, « Petites et moyennes industries de la France rurale », Revue de Géographie de Lyon, $\mathrm{n}^{\circ} 67-3$, p. 173-178.

Lamard P. \& Vitoux M.-C. (dir.), 2006, Les friches industrielles, point d'ancrage de la modernité, Panazol, Lavauzelle, 215 p.

Leniaud J.-M., 1992, L'utopie française, essai sur le patrimoine, Paris, Mengès, 180 p.

Maisonniac N., 2000, « Un pôle industriel au bout du monde : les Boutières (Ardèche) », Revue de l'Économie Méridionale, vol. 48, n¹89-90, p. 63-76.

Nacé Ch. \& Nacé J.-R. ,2008, « L'Ardèche, terre de patrimoine industriel ? », Historiens et Géographes, n401, p. 277-284.

Pitte J.-R., 1983, rééd. 2001, Histoire du paysage français, Paris, Tallandier, 444 p.

Roth H., 2011, « Les « villes rétrécissantes » en Allemagne », Géocarrefour, n86/2, p. 75-80. 
Veschambre V., 2005, « Habiter un lieu de production et de travail : introduction », in GravariBarbas M. (dir.), Habiter le patrimoine. Enjeux, approches, vécu, Rennes, Presses Universitaires de Rennes, p. 511-516.

Veschambre V., 2007, « Patrimoine : un objet révélateur des évolutions de la géographie et de sa place dans les sciences sociales ", Annales de géographie, $n^{\circ}$ 656, p.361-381

Veschambre V., 2008, Traces et mémoires urbaines - Enjeux sociaux de la patrimonialisation et de la démolition, Rennes, Presses Universitaires de Rennes, 315 p.

Vigoureux Ch., 2004, Payen, la tradition vivante, Guilherand-Granges, Impressions Modernes, 72 p.

Thiébaut Y., 2008, Valorisation du patrimoine et aménagement rural. Diagnostic de charte paysagère. Étude de cas sur le territoire de Revigny-sur-Ornain, Rapport de stage de Master 1 à la Communauté de Communes du Pays de Revigny-sur-Ornain, Nancy Université, 116 p.

Sites Internet consultés :

http://geo.uni.lusite de l'atlas de la Grande Région (Luxembourg, Lorraine, Rhénanie-Palatinat, Sarre, Wallonie), proposant, entre autres, des milliers de photos sur le patrimoine industriel, consulté le 23 mars 2012.

www.britishlistedbuildings.co.uk site répertoriant les édifices classés et inscrits au Royaume-Uni, consulté le 13 mars 2012.

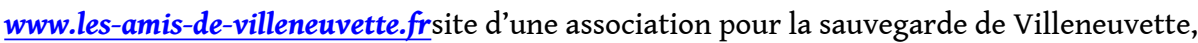
consulté le 6 avril 2012.

$\underline{w w w . i n s e e . f r s i t e ~ d e ~ l ' I n s t i t u t ~ N a t i o n a l ~ d e ~ l a ~ S t a t i s t i q u e ~ e t ~ d e s ~ E t u d e s ~ E c o n o m i q u e s, ~ c o n s u l t e ́ ~ l e ~} 8$ décembre 2011.

\section{NOTES}

1. Désigne une ville entièrement ou presque entièrement créée autour d'une usine par un patron paternaliste (Edelblutte, 2010a).

2. Ce terme désigne les villes-usines particulièrement homogènes créées dans de nombreux pays européens, essentiellement durant l'Entre-deux-guerres, par l'entreprise tchécoslovaque Bata, fabriquant des chaussures.

3. En situation climatique extrême, la fermeture de l'usine-mère peut entraîner la disparition de la ville-usine qui devient alors une ville fantôme, telles les villes minières des Montagnes Rocheuses aux Etats-Unis ou les villes-usines autrefois construites par les prisonniers du Goulag en Russie du Nord.

4. Entretien du 6 avril 2012 avec S. Varinot, COPARY, Revigny-sur-Ornain.

5. Entretien du 2 avril 2012 avec D. Jung, Conservatoire des Sites Lorrains, Bainville-aux-Miroirs.

6. Plus de 400 recensées au XIX ème siècle (Nacé Ch. \& Nacé J.-R., 2008).

7. Entretien du 23 avril 2010 avec G. Barras, co-fondateur d'Ardelaine, Saint-Pierreville.

8. Le grade I désigne des édifices "d'un intérêt exceptionnel », le grade II* des édifices «particulièrement importants et d'un intérêt spécial » et le grade II « des édifices d'un intérêt spécial ».

9. Entretiens réalisés avec Ch. Féroussier et D. Bosc le 21 avril 2010 et avec le Dr. J. Chabal le 22 avril 2010. 


\section{RÉSUMÉS}

Le milieu rural, dans sa diversité, est en général peu perçu comme un espace industrialisé. Les politiques de développement local privilégient le tourisme, l'agriculture, l'accessibilité et les services plus que le maintien ou le renouveau d'un tissu industriel souvent mal connu car peu étudié. Or, c'est bien souvent en milieu rural que le développement industriel des XIX ${ }^{\mathrm{ème}}$ et XX ${ }^{\text {ème }}$ siècles a pris racine, sur des implantations proto-industrielles légères et diffuses mais très nombreuses. Ces implantations ont parfois généré des ensembles plus vastes, comme des villesusines quittant alors le milieu rural ou, plus souvent, des agglomérations plus modestes pouvant être qualifiées de villages-usines. Moulins ou ateliers proto-industriels, usines isolées, modestes villages-usines tombent peu à peu dans l'abandon et l'oubli avec le déclin de l'industrie fordiste. Ils laissent un ensemble de traces, souvent ténues, rarement spectaculaires. Elles sont parfois redécouvertes et valorisées aujourd'hui, mais plus souvent laissées à l'abandon et, au pire, niées ou, au mieux, répertoriées et étudiées sans être valorisées. Au-delà même de ces actions patrimoniales, la redécouverte de l'importance de la culture industrielle dans le développement de certains territoires et la volonté de la maintenir sont aussi une manière de prendre en compte le patrimoine industriel.

Rural areas are generally not perceived as industrialized areas. The local development policies are focusing on tourism, agriculture, accessibility and services so industry, existing plants as well as industrial heritage, is often neglected by authorities or researchers. However, industrial development of nineteenth and twentieth centuries has taken roots in rural areas, on small and scattered, but numerous, proto-industrial mills. These settlements have occasionally evolved to larger units such mill-towns, or company-towns (so they're no more included in rural areas), but the majority stayed small and became a sort of "mill-village" or "company-village". Mills or proto-industrial workshops, remote factories, small "mill-villages" are gradually falling into neglect and oblivion with the decline of fordist industry. It leaves a set of traces, often light and little spectacular. They are sometimes rediscovered and valued today, but more often abandoned and, for worst, denied or, for better, identified and studied without being valued. Beyond these actions for the preservation of heritage, rediscovering the importance of industrial culture in the development of some rural areas and working for keeping it is also a way to consider the industrial heritage.

INDEX

Keywords : industrial archaeology, industrial culture, industrial heritage, industrial landscape, industrial regeneration, proto-industry

Mots-clés : archéologie industrielle, culture industrielle, patrimoine industriel, paysage industriel, proto-industrie, reconversion industrielle

\section{AUTEURS}

\section{SIMON EDELBLUTTE}

Université de Lorraine - LOTERR (Laboratoire d'Observation des Territoires) - Campus Lettres de Nancy - 23, boulevard Albert I ${ }^{\text {er }} 54000 \mathrm{NANCY}$ - simon.edelblutte@univ-lorraine.fr 


\section{JOHANN LEGRAND}

Université de Lorraine - LOTERR (Laboratoire d'Observation des Territoires) - Campus Lettres de Nancy - 23, boulevard Albert I ${ }^{\text {er }} 54000$ NANCY - legrandjohann@laposte.net 